\title{
Epidemiological and Prognostic Profile of Patients Operated for Obliterative Arteriopathy of the Lower Limbs (OALL) at the
} General Hospital of Yaundé - Cameroon

\section{Bassong Mankollo Olga Yvonne ${ }^{*}$, Mbessoh Kengne Ulrich Igor ${ }^{1}$, Fokou Marcus ${ }^{2}$, Tchinda Fossi Cedric 1,3}

1Department of Public Health, School of Health Sciences, Central Africa Catholic University, Cameroon.

2Surgery Department, General Hospital of Yaoundé, Yaoundé, Cameroon.

32Department of Biochemistry, Faculty of Science, University of Yaoundé I, Cameroon.

\section{ABSTRACT}

Introduction: Obliterative Arteriopathy of the Lower Limbs (OALL) is one of the most prevalent cardiovascular diseases in the world with high morbidity and economic impact. In Cameroon, this condition is also present but little studied. For this purpose, this study aims to analyze the epidemiological profile and prognosis of patients operated for OALL at the Yaounde General Hospital (YGH).

Materials and Methods: We conducted a retrospective longitudinal study in the surgery department of the YGH relating to ninety-seven medical records of OALL operated patients between 2008 and 2018 (ten years) using a quantitative research approach.

Results: It emerges from this study that the mean age was $67.1 \pm 13.3$ years. Male sex was predominant (57.7\%). Stroke was the most frequent clinical past history $(15.5 \%)$. The most frequent cardiovascular risk factors were arterial hypertension (63.9\%), diabetes mellitus (41.2\%) and smoking (32.9\%). Grade III-IV and acute limb ischemia were the most prevalent OALL grades (41.2\% and 32\% respectively). Amputation was the most practiced surgical procedure (41.2\%). The one-year mortality rate was $39.2 \%$. We found no factor associated with one-year survival.

Conclusion: We, therefore, suggest that public health actors develop actions and interventions to exercise in order to reduce this health indicator (mortality rate) and revalue the place of psychosocial care in amputees.

Keywords: Epidemiological Profile, Prognosis, Obliterative, Arteriopathy, Lower Limbs,

\section{Address for Correspondence Author}

Dr. Bassong Mankollo Olga Yvonne; Department of Public Health, School of Health Sciences, Central

Africa Catholic University, Cameroon.

E-mail: olgabassong@gmail.com

Crossref Doi: https://doi.org/10.36437/irmhs.2020.3.1.C

\section{Introduction}

Obliterative Arteriopathy of the Lower Limbs (OALL) is defined by the narrowing of the caliber of the arteries that irrigate the lower

limbs, resulting in a hemodynamic loss of load, with or without clinical translation. Cardiovascular disease, like all other diseases, is 
a pathology that is common worldwide, yet for too long neglected [1]. It affects $12-14 \%$ of the general population, and as such is one of the most prevalent cardiovascular diseases in the world, with morbidity, mortality and economic impact equivalent to that of coronary heart disease [2, 3]. According to the Global Burden of Disease Study, OALL affects more than 202 million people worldwide [4], and in the first year of severe lower limb ischemia, 30\% of patients undergo major amputation and $25 \%$ die from the disease [5].

The epidemiological situation in Africa has changed in the last decade with the phenomenon of epidemiological transition, characterized by a decrease in communicable diseases and an increase in chronic non-communicable diseases, among which cardiovascular diseases stand out for their prevalence [2]. Indeed, recent population-based studies in Central Africa have reported high prevalence of OALL among people over 65 years of age, ranging from $11.5 \%$ to $20.7 \%$, in both urban and rural areas [4].

If the Western scientific literature overabundantly questions the OALL's problematic [5-10], it is not the same in Africa and in Cameroon in particular where studies on this pathology are rare. Thus, it is to contribute to filling this gap in data and scientific knowledge on this issue in our context that we undertook to conduct this research on the epidemiological and prognostic profile of patients operated on OALL at the Yaounde General Hospital (YGH).

Materials and Methods: This was a retrospective longitudinal study conducted at the surgery department of the Yaounde General Hospital over 04 months, from October 2019 to January 2020. We thus surveyed the medical records of patients operated on for OALL between 2008 and 2018, using a non-probability quota sampling design. The quota was not defined as a priori but.

Inclusion Criteria: Medical records of patients operated on for OALL in the YGH surgery department between 2008 and 2018 .

Exclusion Criteria: Altered, illegible medical records and those that did not provide all of the required information for the study period.

Data was collected from an observation grid developed on the model of the COPART (COhorte des Patients ARTériopathes) Registry questionnaire. The COPART Registry is a prospective multi-centre hospital-university cohort study conducted in France between 2008 and 2010 by Cambou et al. [11]. This grid has therefore been adapted to the specifically Cameroonian context and validated by a college of YGH surgeons. It is composed of 07 parts that successively provide information on sociodemographic characteristics, clinical history, cardiovascular risk factors, clinical stage of OALL evolution, diagnostic medical imaging examinations, surgical therapies administered, and the survival of the operated patients at 01 year. The information on these variables contained in the patient's medical records was entered into the observation grid for analysis. The data recorded on the grid were entered into a specially designed input mask in CS Pro version 7.0 software and then exported to SPSS version 23.0 software for statistical analysis. Quantitative variables were presented as mean and standard deviation and qualitative variables as headcount and percent. Chi-2 and Fischer's exact tests were used as appropriate to compare the categorical variables and the statistical significance threshold was $5 \%$. 
Ethical Considerations: To respect medical ethical considerations, we ensured the confidentiality of all patient records during the study. This study was operationalized after approval by the Institutional Ethics Committee for Research in the Human Sciences (CEIRSH) of the School of Health Sciences of the Catholic University of Central Africa No. 2019/020145/CEIRSH/ESS/MSP.

\section{Results}

\section{Socio-demographic Characteristics of Patients Operated for OALL at YGH}

The mean age of the patients in our sample was $67.1 \pm 13.3$ years. The age ranged from 27 to 90 years. The age group 70 to 80 years was the most represented (38.1\%). Males predominated (57.7\%) with an M/F sex ratio of 1.37 (Table 1).

\begin{tabular}{|l|l|l|}
\hline Sociodemographic Characteristics & Effectifs & Percentage (\%) \\
\hline Age & & \\
\hline$[20-30[$ & 15 & 1,0 \\
\hline$[30-40[$ & 13 & 5,2 \\
\hline$[40-50[$ & 13 & 6,2 \\
\hline$[50-60[$ & 9 & 10,3 \\
\hline$[60-70[$ & 9 & 21,6 \\
\hline$[70-80[$ & 3 & 38,1 \\
\hline$[80-90]$ & 2 & 17,5 \\
\hline Sex & & \\
\hline Male & 56 & 57,7 \\
\hline Female & 41 & 42,3 \\
\hline
\end{tabular}

Table 1: Sociodemographic Characteristics of the Study Population

\section{Clinical Characteristics of Patients Operated for OALL at YGH}

Table .2 shows that Vasculo-cerebral accident was the most common clinical history (15.5\%), while the main cardiovascular risk factors were hypertension (63.9\%), diabetes (41.2\%), and smoking (32.9\%). For the Rutherford classification, grades III-IV and acute/subacute ischemia were the most common stages of OALL evolution ( $41.2 \%$ and $32 \%$ respectively). 


\begin{tabular}{|l|l|l|}
\hline Caractéristiques Cliniques & Effectifs & Pourcentages (\%) \\
\hline Clinical History & & \\
\hline Vasculo-cerebral Accidents & 15 & 15,5 \\
\hline Peripheral Bypass & 13 & 13,4 \\
\hline Amputation & 13 & 13,4 \\
\hline Heart Failure & 9 & 9,3 \\
\hline Atrial Fibrillation & 9 & 9,3 \\
\hline Cardiovascular Risk Factors & & \\
\hline Hypertension & 62 & 63,9 \\
\hline Diabetes & 40 & 41,2 \\
\hline Smoking & 24 & 32,9 \\
\hline Clinical Grades from OALL & 17 & \\
\hline Grade I & 9 & 17,5 \\
\hline Grade II & 40 & 9,3 \\
\hline Grade III-IV & 31 & 41,2 \\
\hline Acute / Subacute Ischemia & 32,0 \\
\hline
\end{tabular}

Table 2: Clinical Characteristics of the Study Population

In terms of surgical therapies administered to patients, amputation was the most common surgical procedure performed as part of management (41.2\%) (Graph1).

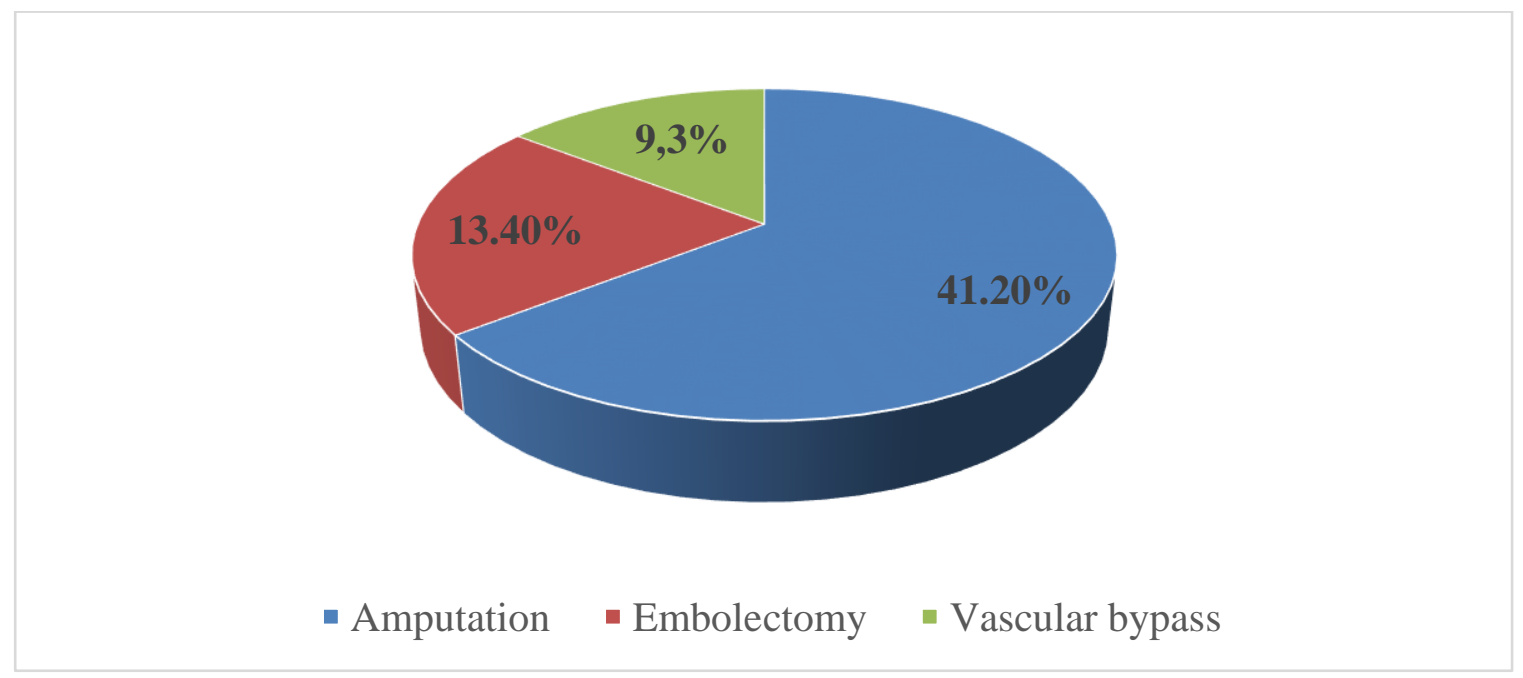

Graph 1: Distribution of surgical therapies administered in the study population. 
In terms of 01-year post-operative survival, Graph 2 shows that the 01-year death rate was 39.2\%.

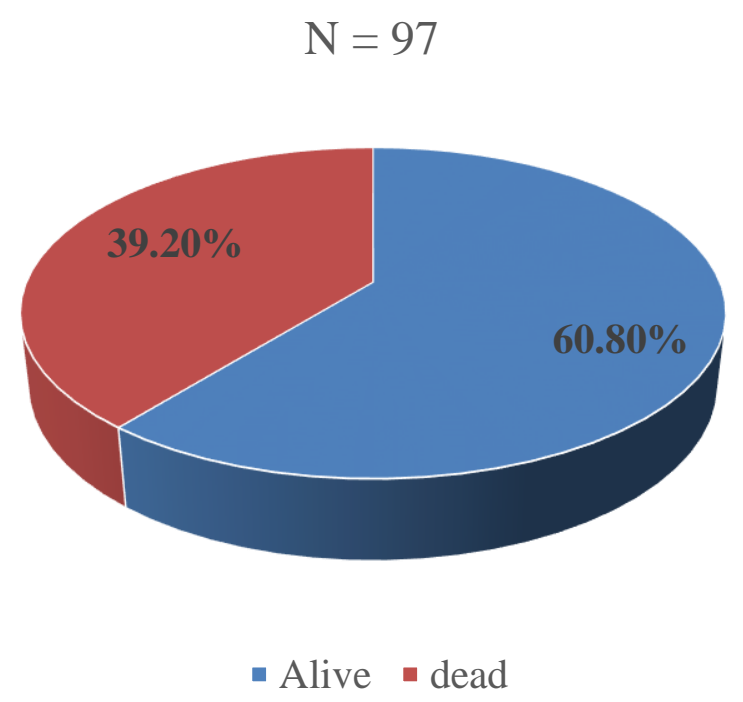

\section{Graph 2: Distribution of Participants by Death Rate.}

No factors significantly associated with the 01-year survival of patients operated on for OALL at YGH were found in this study (Table 3).

\begin{tabular}{|l|l|l|l|l|}
\hline \multirow{2}{*}{ Variables } & \multicolumn{2}{|l|}{ 01-year survival } & \multirow{2}{*}{ HR (95\%CI) } & P-Valeur \\
\cline { 2 - 3 } & \multicolumn{2}{|l|}{ Alive } & Dead & \\
\hline$[70-80[$ & $18(48.6)$ & $19(51.4)$ & $0.4(0.2-1.02)$ & 0.054 \\
\hline Male Gender & $37(66.1)$ & $19(33.9)$ & $1.7(0.7-3.8)$ & 0.216 \\
\hline $\begin{array}{l}\text { Vasculo-Cerebral } \\
\text { Accidents }\end{array}$ & $11(73.3)$ & $4(26.7)$ & $1.9(0.6-6.6)$ & 0.280 \\
\hline Hypertension & $38(61.3)$ & $24(38.7)$ & $1.1(0.5-2.5)$ & 0.901 \\
\hline Diabetes & $22(55)$ & $18(45)$ & $0.7(0.3-1.5)$ & 0.325 \\
\hline Smoking & $18(75)$ & $6(25)$ & $2.3(0.8-6.6)$ & 0.101 \\
\hline Grade II & $8(88.9)$ & $1(11.1)$ & $5.8(0.7-48.4)$ & 0.085 \\
\hline Grade III-IV & $21(52.5)$ & $19(47.5)$ & $0.6(0.2-1.3)$ & 0.159 \\
\hline $\begin{array}{l}\text { Acute / Subacute } \\
\text { Ischemia }\end{array}$ & $22(71)$ & $9(29)$ & $1.9(0.8-4.8)$ & 0.161 \\
\hline Amputation & $9(69.2)$ & $4(30.8)$ & $1.5(0.4-5.4)$ & 0.505 \\
\hline
\end{tabular}

Table 3: Factors Associated with 01 Year Survival 


\section{Discussion}

Socio-demographic Characteristics $>$ Age

The average age was 67, with the youngest subject being 27 and the oldest subject being 90. In addition, the age group most affected was 60 to 80 years of age, which accounted for $59.7 \%$ of cases (Table 1). These results establish OALL as a frequent condition in subjects over 50 years old and are similar to those found by Zoumanigui et al. [12] in Guinea-Conakry, Okello et al. [9] in Uganda and Cambou et al. [11] in France. This similarity can be explained by the fact that age is now recognized in the literature as a risk factor for OALL. In addition, patients in this age group are more exposed to several cardiovascular risk factors including hypertension, diabetes, and atherosclerosis [12].

However, with an average age of 81 years reported in their study and extremes of 44 and 99 years, Tisserand et al. [13] do not corroborate our results. This could be due to the particularity of their study population. Indeed, their study involved a population of geriatric patients with heel ulcers in whom they were studying the prevalence and severity of OALL. It is, therefore, a specific and essentially senile population, whereas our study population was younger.

\section{$>$ Sex}

We found a male predominance at $57.7 \%$, which is clearly in line with the literature $[1,7$, $11,13]$. Indeed, in all prevalence studies, a male-to-female ratio is found, 2:1 (twice as many men as women) in the intermittent claudication stage and from 3:1 (three times as many men as women) to $13: 1$ (thirteen times as many men as women) in the more advanced stages. Gender differences decrease with age, as age-related menopause in women is now recognized as a cardiovascular risk factor [14].
In this sense, it increases a woman's risk of developing OALL with age, which consequently tends to increase the sex ratio.

However, some series contrast and show a predominance of women. This is the case of Okello et al. [9] who rather reported a female predominance. This difference could be attributed to the fact that their study focused on a specific population of diabetic patients whereas our study population showed some heterogeneity in terms of the comorbidities associated with OALL. Indeed, studies that have questioned the prevalence and risk factors of OALL in specific populations such as diabetics and people living with HIV/AIDS have shown a predominance of females $[8,15]$. We could put forward the explanatory hypothesis that this female predominance is rather a reflection of the epidemiology of diabetes and HIV/AIDS, which in Africa and Cameroon, in particular, has a sex ratio in favour of women $[8,15]$.

\section{Clinical Features}

\section{* Clinical History}

Vasculo-cerebral accident, bypass surgery, amputation, heart failure, atrial fibrillation, coronary artery disease, chronic kidney disease and peripheral angioplasty were the main clinical histories found in patients. The common denominator of these pathologies is that they all fall within the nosological framework of cardiovascular disease. The same clinical history is included in the French COPART registry, albeit in varying proportions, but generally reflects the burden of cardiovascular morbidity associated with the OALL [11].

Indeed, patients with arterial claudication of the lower limbs have diffuse atherosclerosis. This explains the frequency of intercurrent events such as Vasculo-cerebral accident, MI or cardiovascular death [14]. Ten percent of patients with claudication have 
cerebrovascular involvement and 28\% have coronary pathology. The latest studies show an annual incidence of non-fatal MI of 1-3\% [14].

The Edinburgh artery study showed a relative risk of 2.31 (95\% CI: 1.04-5.10) of angina in patients with claudication, whereas the risk is lower, but present, in asymptomatic forms.

\section{* Cardiovascular Risk Factors}

Hypertension, diabetes, smoking (current or past), obesity, physical inactivity, HIV infection, and dyslipidemia are the cardiovascular risk factors highlighted in our study. These factors are known and found in the literature [11- 15].

Smoking: The relationship between smoking and OALL has been known for many years. The Framingham study provided the strongest epidemiological correlations. There is a 3 -fold risk of OALL in smokers. Moreover, the damage is proportional to the importance of the intoxication. After quitting smoking, the risk does not disappear for all that. Fowkes et al. [16] show a relative risk (RR) of OALL of 3.7 in case of active intoxication, and three after five years of cessation.

Cognitive behavioural theories also allow us to explain this link between smoking and OALL. Current theories of behavioural change approach the idea that an individual's intentions are an essential factor in behaviour. The basic assumption is the same: preventive behaviour results from the perception of a threat and the belief that the best course of action is to adopt a new behaviour. Taking this as a corollary, it can be said that smokers persist in this behaviour because they do not perceive the threat that smoking poses to cardiovascular health, and this could be explained by the fact that popular thought only recognises tobacco as a risk factor for lung cancer and does not socioculturally represent its link with cardiovascular disease, and therefore the intention to stop smoking to prevent the occurrence of OALL does not appear in these patients.

Diabetes: Fifty percent of amputations and $28 \%$ of revascularization surgeries involve diabetics. Especially since it is common to find the conjunction of several risk factors (hypertension, dyslipidemia). Finally, according to a recent study, carbohydrate intolerance increases the risk of developing lower limb arteriopathy by a factor of two to four [14].

Cognitive theoretical approaches to behaviour recognise the complexity of human behaviour, taking into account not only cognition but also other equally important determinants such as context (environment, surroundings, medical factors, socio-demographic factors, associated factors, pollution, lifestyle or habit). In this sense, the influence of medical factors such as diabetes determines the occurrence of OALL in diabetic patients.

Hypertension: It is always the Framingham study that provides the most restringente information. Thus the risk of OALL is multiplied by 2.5 in a hypertensive man and 3.9 in a woman. The annual incidence in normotensive men is $2.5 \%$ and $6.2 \%$ in hypertensive men 0.8 and 3 respectively in women). Paradoxically, however, hypertension can preserve symptoms of claudication for a period of time by increasing distal pressures. Sometimes medical treatment may be the indicator of the condition [14].

Cognitive theoretical approaches to behaviour recognise the complexity of human behaviour, which takes into account not only cognition but also other equally important determinants such as context (environment, surroundings, medical factors, socio-demographic factors, associated factors, pollution, lifestyle or 
habits). In this sense, the influence of medical factors such as high blood pressure determines the occurrence of OALL in hypertensive patients.

Dyslipidémie: A total cholesterol level $>2.7$ $\mathrm{g} / \mathrm{L}$ doubles the risk. The ratio of total cholesterol to HDL cholesterol is the strongest predictor. Treatment of hypercholesterolemia decreases the progression of OALL and the incidence of lower limb lameness. Studies on hypertriglyceridemia are still contradictory [14].

\section{* Clinical Grade}

According to Rutherford's classification, Clinical Grades III and IV were the most represented, followed by intermittent arterial claudication with $41.2 \%$ and $17.5 \%$. Critical ischemia was present in $32 \%$ of patients. These findings are close to those reported in the COPART registry in France [11]. Still qualified as severe OALL, grades III and IV indicate the use of surgical therapeutic procedures for their management, which could explain why they are the most represented. On the other hand, it is at these stages that the patient experiences a permanent painful symptomatology that causes unpleasant discomfort in his daily activities, which leads him to consult a doctor and ask for treatment.

Cognitive theories of health behaviour also contribute to understanding why grades III-IV are predominant. Indeed, we can explain the predominance of severe OALL grades by the lack of perception by patients of the threat represented by this condition during its evolution. Cognition is reinforced by the insidious and silent evolution of the disease which leads to late recourse to care at advanced stages, when surgery proves to be unavoidable for curative management.

\section{Surgical Therapies Administered}

Amputation (41, 2\%), embolectomy $(13,4 \%)$ and vascular bypass $(9,3 \%)$ are the most common surgical procedures performed in our study. In the COPART registry, angioplasty was the most commonly performed procedure (30, $3 \%$ ), followed by amputation $(17,2 \%)$ and then vascular bypass $(10,1 \%)$ [11]. Thus, almost half of the patients in our series had at least one limb amputated. In critical ischemic situations, the amputation rate is between 10 and $40 \%$, depending on the studies, with an average of $25 \%$ at one year of evolution [14]. Collins et al. [7] reported an amputation rate of $13.9 \%$ versus $17.1 \%$ vascular bypass.

The literature indicates that the amputation of a lower limb is associated with a deterioration in the physical, psychological and mental state of the patient and a notorious alteration in his quality of life, while vascular bypass surgery, although less devastating than amputation, is nevertheless associated with a mortality rate of 2 to $8 \%$ in the first 30 days post-operatively. In addition, patients who have undergone vascular bypass surgery have a $20 \%$ risk of secondary amputation within 5 years [7]. However, this high amputation rate can be associated with the $41.2 \%$ of patients with advanced OALL grade (grade III and IV) who have had to undergo amputation of severely affected limbs as a result.

Compared to the COPART registry, the nonpractice of angioplasty in our context would possibly be linked on the one hand to the lack of an adequate technical platform allowing the practice of this type of surgery, and on the other hand to the financial inability of most applicants to pay the cost of this type of intervention in a precarious socio-economic context where universal health coverage is still hardly a reality. 
According to theories on health behavior, the choice of the surgical procedure practiced by the vascular surgeon among several other surgical alternatives in the context of the management of OALL is intentional; it follows from the latter's belief that it is the best procedure to adopt, taking into account the patient's clinical situation, this belief being itself partly based on evidence-based medicine and partly on its personal experience as a clinician. This cognitive determinant linked to the choice of operating procedure could be beneficial or fatal for the patient in terms of post-operative survival.

\section{1-Year Survival Rate}

In our study, the prognosis for OALL is poor, with a dramatic 01-year mortality of $39.2 \%$. In the COPART registry, the reported mortality rate is $21.4 \%$, most of which is due to cardiovascular causes [11]. In the Swedish National Registry, 21\% of patients died within one year of diagnosis of OALL and approximately 1 in 6 patients had MI, Vasculocerebral accident or cardiovascular death within one year. Their hospitalization rate is high and their morbi-mortality rate is higher than that of myocardial infarction. Often, these patients also suffer from serious comorbidities such as diabetes, kidney, heart or respiratory failure [1]. In Great Britain, mortality has been estimated at $20 \%$ at one year. In an Italian observational study of 574 patients, at three months, mortality was $8.7 \%$, myocardial infarction rate $0.5 \%$, and Vasculocerebral accident rate $1 \%$. Mortality at one year is $21.9 \%$ [1]. These data corroborate those of many other series that show that seventy-five percent of patients with lower limb arterial disease will die of cardiac or cerebrovascular causes.

\section{Factors Associated with Survival}

We found no statistically significant factors associated with survival. This result could be attributed to the small sample size, which substantially affected the power of the statistical tests used, since in the COPART registry that enrolled 1009 patients with OALL, Cambou et al. [11] reported that the presence of cardiovascular comorbidities, the clinical grade of the advanced disease and age over 70 years increased the risk of death in the first year. In addition, other studies report smoking, gender, diabetes and hypertension as other associated factors [14]. What these studies have in common is that they have involved much larger samples than we have. Indeed, the small sample size would have contributed to diminishing the statistical power of our analysis, thus masking significant associations.

Conclusion: The epidemiological profile of the patients operated on for OALL at the YGH is marked by the striking fact that almost half of the patients have at least one limb amputated, but the amputation of a lower limb leads to a marked deterioration in the patient's physical, psychological and psychological state and a significant deterioration in their quality of life. The prognosis for these patients remains poor, with a death rate of $39.2 \%$ in the first year. These results call for and commit the responsibility of public health actors to develop actions and interventions to be carried out in order to influence this health indicator (mortality rate), and bring the issue of the place of psychosocial care of patients in surgery back into the spotlight.

Acknowledgements: The authors thank the staff of the Surgery, Department of the General Hospital of Yaoundé for facilitating access and data collection within the Surgery Department. 


\section{References}

1. Sprynger, M., Maréchal, P., Moonen, M.,Martinez, C., \&Lancellotti, P. (2019). Artériopathie oblitérante des membres inférieurs: Angioplastie et stenting en 2019. Revue Médicale de Liège, 74, 57-63.

2. Desormais, I. S. (2014). Artériopathie oblitérante des membres inférieurs en Afrique Centrale: Epidémiologie, facteurs de risque, marqueur pronostique (Thèse). Université de Limoges, France.

3. Mahad, R. (2016). L'artériopathie oblitérante des membres inférieurs chez les patients à haut risque (Thèse, Faculté de Médecine et Pharmacie de Marrakech). Consulté à l'adresse http://wd.fmpm.uca.ma/biblio/theses/ annee-htm/FT/2016/these116-16.pdf

4. Guerchet, M. (2018). Artériopathie oblitérante des membres inférieurs en Afrique subsaharienne: Une maladie rare? Journal de Médecine Vasculaire, 43(2), 86.

5. AA Bediako-Bowan, A., O Adjei, G., N Clegg-Lamptey, J., \& B Naaeder, S. (2017). The burden and characteristics of peripheral arterial disease in patients undergoing amputation in Korle $\mathrm{Bu}$ Teaching Hospital, Accra, Ghana. Ghana Medical Journal, 51(3), 108-114.

6. Andreassian, B., Bonithon-Kopp, C., Bonnet, J., Becker, F., Drouet, L., Dumont, E., Simon, A. (1994). Arthériopathie des membres inférieurs: Dépistage et risque cardiovasculaire (INSERM). INSERM.

7. Collins, T. C., Nelson, D., \& Ahluwalia, J. S. (2010). Mortality following operations for lower extremity peripheral arterial disease. Vascular
Health and Risk Management, 6, 287-296.

8. Kamdem, F., Mapoure, Y., Ba, H., Souksouna, F., Doualla, M. S., Musa Jingi, A., ... \&Luma, H. (2018). Prevalence and risk factors of peripheral artery disease in black Africans with HIV infection : A cross-sectional hospital-based study. Vascular Health and Risk Management, 14, 401-408.

9. Okello, S., Millard, A., Owori, R., Bambeiha Asiimwe, S., Siedner, M. J., Rwebembera, J., ... \&Herb Annex, B. (2014). Prevalence of lower extremity Peripheral artery disease among adult diabetes patients in Southwestern Uganda. BMC Cardiovascular Disorders, $14,75$.

10. Touré, L., Moussa, A., Traoré, T., Traoré, S., Sidibé, O., Diallo, A., ... \&Kéita, S. (2018). Les causes des amputations majeures des membres à l'Hôpital de Sikasso. Mali Médical, 33(3), 15-18.

11. Cambou, J. P., Aboyans, V., Constans, J., Lacroix, P., Dentans, C., \& Bura, A. (2010). Characteristics and Outcome of Patients Hospitalised for Lower Extremity Peripheral Artery Disease in France: The COPART Registry. European Journal of Vascular and Endovascular Surgery, 39(5), 577-585.

12. Zoumanigui, N., Tolno, S. K., Nchare, C., \& Diaoune, A. (2010). Artériopathies oblitérantes des membres inférieurs (OALL) : A propos de 33 observations dans le service de cardiologie médicochirurgicale, hôpital national de Donka. Annales Africaines de Chrirugie Thoracique et Cardiovasculaire, 5(2), 82-88.

13. Tisserand, G., Zenati, N., Seinturier, C., Blaise, S., \& Pernod, G. (2017). Prevalence and severity of peripheral 
arterial disease among patient with heel pressure ulcer: A retrospective study of 42 patients. Gériatrie et Psychologie Neuropsychiatrie du Viellissement, 15(3), 242-246.

14. Marchand, G. (2001). Épidémiologie et facteurs de risque de l'artériopathie oblitérante des membres inférieurs. Annales de Cardiologie et d'Angéiologie, 50(2), 119-127.

15. Konin, C., Essam N'loo, A. S., Adoubi, A., Coulibaly, I., N'guetta, R., Boka, B., ... \&
Adoh, M. (2014). Artériopathie des membres inférieurs du diabétique noir africain: Aspects ultrasoniques et facteurs déterminants. Journal des Maladies Vasculaires, 39(6), 373-381.

16. Fowkes,G., Aboyans, V., Sevestre, M. A., Désormais, I., Lacroix, P. (2018). Epidémiologie de l'artériopathie des membres inférieurs. La Presse médicale, $\quad 47(1)$ : 38-46.

How to cite this Article: Bassong Mankollo Olga Yvonne ${ }^{1 *}$, Mbessoh Kengne Ulrich Igor ${ }^{1}$, Fokou Marcus $^{2}$, Tchinda Fossi Cedric ${ }^{1,3}$; Epidemiological and Prognostic Profile of Patients Operated for Obliterative Arteriopathy of the Lower Limbs (OALL) at the General Hospital of Yaoundé - Cameroon

Int. Res. Med. Health Sci., 2020; (3-1): 1-8

Source of Support: Nil,

Conflict of Interest: None declared.

Received: 20-1-2020; Revision: 17-2-2020; Accepted: 25-02-2020 